\title{
OCORRÊnCia de Lithadia Rotundata A. Milne EdWards, 1880 no Litoral BRASILEIRo (CRUSTACEA: BRACHYURA: LEUCOSIIDAE).
}

\author{
MARIA FERNANDA ABRANTES TORRES ${ }^{(1)}$ \\ Gustavo Augusto Schmidt de Melo ${ }^{(2)}$ \\ 1 - Departamento de Oceanografia-UFPE \\ 2 - Museu de Zoologia-USP
}

\begin{abstract}
RESUMO
O gênero Lithadia Bell está representado, no Brasil, por quatro espécies: L. brasiliensis (von Martens, 1872), L. conica (Coelho, 1973), L. obliqua (Coelho, 1973) e L. vertiginosa (Coelho, 1973), todas endêmicas para a costa brasileira. Lithadia rotundata, descrita por A. Milne Edwards (1880), está referida, até o momento, apenas para o litoral argentino. No material coligido durante o Projeto Crustáceos Decápodes da costa Riograndina, realizado entre março de 1982 e dezembro de 1984, pelo N. Oc. "Atlântico Sul", foram encontrados dois espécimes machos de L. rotundata, coletados na estação 17 do Cruzeiro 1 , localizada a $32^{\circ} 18^{\prime} 00^{\prime \prime}$ S: $51^{\circ} 37^{\prime} 00^{\prime \prime} \mathrm{W}, 21$ metros de profundidade, substrato de areia, temperatura de $23,3^{\circ} \mathrm{C}$ e salinidade de 34 e encontram-se depositados na Coleção Carcinológica da Fundação Universidade do Rio Grande (FURG).
\end{abstract}

Palavras-chave: Lithadia rotundata, ocorrência, litoral brasileiro.

\author{
Abstract \\ Occurrence of Lithadia Rotundata A. Milne Edwards, 1880 in the Brazilian Coast \\ Crustacea:Brachyura:Leucosiidae)
}

The genus Lithadia Bell is represented in Brazil by four species: L. brasiliensis (von Martens, 1872), L. conica (Coelho, 1973), L. oblique (Coelho, 1973) and L. vertiginosa (Coelho, 1973), all endemic to the Brazilian coast. Lithadia rotundata, described by A. Milne Edwards (1880), has been referred, until now, only off the Argentinian littoral. Two male specimens of $L$. rotundata were found among the material gathered during the "Crustaceans Decapods off Rio Grande coast Project", realized between March/1982 and December/1984, by "Atlântico Sul" Oceanographic Vessell, collected in the station 17 of the Cruise $1,32^{\circ} 18^{\prime} 00^{\prime \prime} \mathrm{S}$ : $51^{\circ} 37^{\prime} 00^{\prime \prime} \mathrm{W}, 21 \mathrm{~m}$, sandy bottom, temperature of $23,3^{\circ} \mathrm{C}$ and salinity of 34 and are deposited in the Carcinological Collection of Rio Grande University Foundation (FURG).

Keywords: Lithadia rotundata, occurrence, Brazilian littoral.

\section{INTRODUÇÃO}

O gênero Lithadia foi erigido por Bell (1855), com Lithadia cumingii, e suas espécies encontram-se distribuídas no Atlântico ocidental e Pacífico oriental. No Atlântico ocidental são

Tropical Oceanography, Recife, v. 29, n. 1, p. 31-35, 2001. 
conhecidas nove espécies, sendo quatro endêmicas para o Brasil: L. brasiliensis (von Martens, 1872), L. conica (Coelho, 1973), L. obliqua (Coelho, 1973) e L. vertiginosa (Coelho, 1973). L. obliqua e L. vertiginosa são assinaladas para o Norte e Nordeste do Brasil, ambas com limite norte no Pará e sul em Pernambuco e Bahia, respectivamente. Por outro lado, L. conica e L. brasiliensis distribuem-se desde o Norte até o Sudeste, a primeira com limite meridional no Espírito Santo e a segunda, em São Paulo.

Lithadia rotundata foi descrita por A. Milne Edwards (1880) e referida para o litoral argentino; este registro foi confirmado posteriormente por A. Milne Edwards \& Bouvier (1902).

Rathbun (1937), em seu inventário sobre os Oxystomata das Américas, examinou o material tipo e considerou a espécie como pertencendo ao gênero Ebalia.

Estudando a distribuição dos crustáceos decápodos marinhos da Argentina, Boschi (1979) citou a ocorrência de Ebalia rotundata (= L. rotundata) nas sub-regiões Temperada Fria e Temperada Quente.

Mais recentemente, Boschi, Fischbach \& Iorio (1992) assinalaram a presença de vários exemplares ao longo do litoral argentino e consideraram, também, esta espécie como pertencendo ao gênero Ebalia.

Souza (1997), estudando os Brachyura da plataforma meridional do Rio Grande do Sul, registrou a presença de espécimes de Lithadia que ele considerou como sendo de Lithadia obliqua, espécie muito semelhante a $L$. rotundata, porém, até então, restrita ao Norte e Nordeste do Brasil.

Desta forma, visando confirmar a ocorrência de Lithadia obliqua para o Rio Grande do Sul, os espécimes estudados por Souza (1977) foram presentemente analisados e a comparados com exemplares de L. rotundata provenientes da Argentina.

\section{MATERIAL E MÉTODOS}

O material estudado foi coletado durante o projeto "Crustáceos Decápodos da costa Riograndina", realizado entre março de 1982 e dezembro de 1984, pelo N. Oc. "Atlântico Sul" e encontra-se depositado na Coleção Carcinológica da Fundação Universidade do Rio Grande (FURG).

São fornecidos: sinonímia, localidade-tipo, redescrição, registros anteriores, material examinado, distribuição geográfica e dados ecológicos.

Foram utilizadas as seguintes siglas:

Mzusp (Museu de Zoologia da Universidade de São Paulo);

Doufpe (Departamento de Oceanografia da Universidade Federal de Pernambuco).

\section{RESULTADOS}

Lithadia rotundata A. Milne Edwards, 1880.

Figura 1

Lithadia rotundata A. Milne Edwards, 1880:22.- A. Milne Edwards \& Bouvier, 1902:113, pr. 22 , fig. 6,7 ; pr. 23 , fig. 1,2 .

Ebalia rotundata; Rathbun, 1937:135, pr. 36, fig. 9-12; pr. 37, fig. 4,5 - Boschi, Fischbach \& Iorio, 1992:58, fig. 62.

Lithadia obliqua; Souza, 1997:37 [non L. obliqua Coelho, 1973 (=L. rotundata A. Milne Edwards, 1880)].

Localidade-tipo. - Patagônia, Argentina.

Tropical Oceanography, Recife, v. 29, n. 1, p. 31-35, 2001. 
Redescrição - Carapaça suboctogonal, ligeiramente mais larga do que longa, irregular, erodida, coberta por grânulos arredondados e achatados, dispostos irregularmente. Fronte estreita, fracamente bilobada. Margens ântero-laterais longas e sinuosas. Margens laterais pouco mais da metade do comprimento das margens ântero-laterais, levemente côncavas ou quase retas. Margens póstero-laterais pouco mais longas do que a precedente, ligeiramente côncavas. Margem posterior cerca de duas vezes a largura da fronte, com sinus largo e dois lóbulos rasos, mais pronunciados nos machos. Regiões hepáticas deprimidas, formando grande concavidade oblíqua acompanhando as margens laterais. Regiões subhepáticas convexas. Regiões branquiais correspondendo à porção mais elevada da carapaça. Região cardíaca com proeminência oblonga, circundada por depressão e ligada à região urogástrica por uma faixa transversal; esta depressão estreita e rasa posteriormente, torna-se mais profunda e larga nas porções lateral e anterior, com um estreitamento entre estas, em função de proeminência da margem externa desta depressão, que se projeta em direção ao ângulo cardíaco anterior. Regiões pterigostomianas bastante convexas, com proeminência arredondada. Olhos e órbitas pequenos. Quelípodos curtos, granulosos; mero com fileira de tubérculos na face superior; palma intumescida na extremidade proximal da face inferior e face superior laminada; dátilo e pólex delgados, com carenas longitudinais. Patas ambulatórias curtas, granuladas e cristadas; mero dos três primeiros pares com carena granulosa na face superior; carpo e própodo com duas fileiras de espinhos nas margens superiores e uma na inferior; dátilo espinhoso e com pilosidade curta. Machos com somitos abdominais 3-5 fusionados; sexto somito com espinho agudo dirigido para trás na extremidade proximal; fêmeas com somitos 4-6 fusionados. Abdome totalmente granuloso e erodido.

Registros anteriores. - Brasil: Rio Grande do Sul (Souza, 1997; como L. obliqua). Argentina (A. Milne Edwards, 1880; A. Milne Edwards \& Bouvier, 1902; Rathbun, 1937; Boschi, 1979; Boschi, Fischbach \& Iorio, 1992)

Material examinado. - Rio Grande do Sul: "Atlântico Sul”, 2 machos, Cruzeiro I, estação 17, 32 18' 00" S:51 37' 00" W, 18/03/82, 21 metros, areia, 23,3 C, 34 de salinidade (FURG-lote 885).

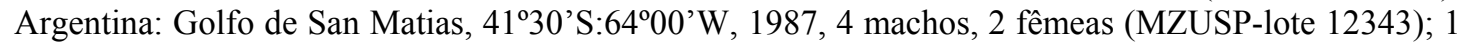
macho, 1 fêmea (DOUFPE).

Distribuição geográfica. - Atlântico ocidental: Brasil (Rio Grande do Sul) e Argentina.

Dados ecológicos. - Coletada a 21 metros de profundidade e em fundo de areia, no Rio Grande do Sul. $\mathrm{Na}$ Argentina a espécie foi registrada entre 20 e 80 metros de profundidade, segundo Boschi, Fischbach \& Iorio (1992).
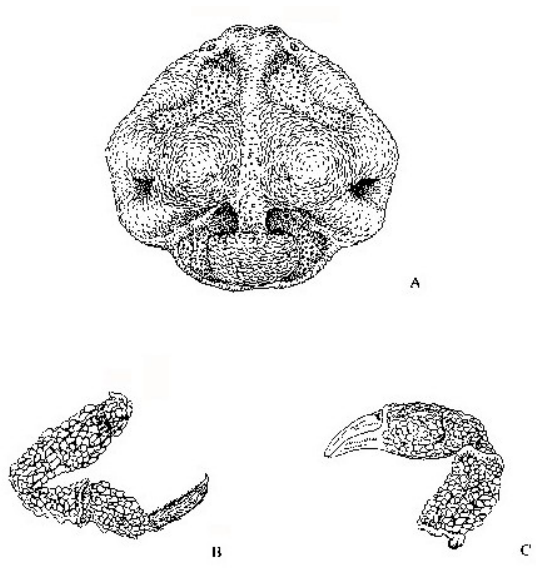

Tropical Oceanography, Recife, v. 29, n. 1, p. 31-35, 2001. 
Figura 1 - Lithadia rotundata A. Milne Edwards. Macho: A, vista dorsal da carapaça (18X); B, pata ambulatória (20X); C, quelípodo (10X).

\section{Comentários}

A partir da revisão dos espécimes provenientes do Rio Grande do Sul, estudados anteriormente por Souza (1997) e referidos como Lithadia obliqua, foi possível constatar que se tratam de exemplares de L. rotundata.

Rathbun (1937), Boschi (1979) e Boschi, Fischbach \& Iorio (1992) consideraram esta espécie como pertencendo ao gênero Ebalia. De acordo com as características morfológicas citadas por Coelho \& Ramos-Porto (1986), para distinção dos gêneros Ebalia e Lithadia (este último com carapaça octogonal e com porção mais elevada nas regiões branquiais de cada lado da região gástrica), $L$. rotundata realmente se enquadra na diagnose do gênero, tal como originalmente descrito por A. Milne Edwards (1880).

Embora sejam conespecíficos, o material brasileiro difere, em alguns caracteres, do argentino: no primeiro, a margem posterior é quase reta, enquanto os espécimes argentinos apresentam a margem posterior nitidamente bilobada; as patas ambulatórias possuem apenas fileiras de grânulos e não cristas bem acentuadas, como no caso dos exemplares da Argentina. Também o esterno, o abdome e os terceiros maxilípodos são mais granulosos no material brasileiro, assim como a carapaça é mais irregular e as erosões são mais rasas e granuladas.

\section{Agradecimentos}

Os autores agradecem ao Prof. Dr. Enrique Boschi, do Instituto Nacional de Investigación y Desarrollo Pesquero, Mar del Plata, Argentina e ao Prof. MSc. José Afonso Feijó de Souza, da Fundação Universidade do Rio Grande, RS, pelo empréstimo e doação de exemplares.

\section{REFERÊNCIAS BIBLIOGRÁFICAS}

BELL, T. XXXI. Horae Carcinologicae, or Notices of Crustacea. I. A Monograph of the Leucosiadae, with observations on the relations, structure, habits and distribution of the family; a revision of the generic characters, and descriptions of new genera and species. Trans. Linn. Soc. London, London, v. 21, n.4, p.277-314, 1855.

BOSCHI, E. E. Geographic distribution os Argentinian marine decapod crustaceans. Bull. Biol. Soc. Wash., Washington, v 3, p.134-143, 1979.

BOSCHI, E. E.; FISCHBACH, C. E.; IORIO, M. I. Catalogo ilustrado de los crustaceos estomatopodos y decapodos marinos de Argentina. Frente Maritimo, Montevideo, v. 10, p.7-94, 1992.

Tropical Oceanography, Recife, v. 29, n. 1, p. 31-35, 2001. 
COELHO, P. A.; RAMOS-PORTO, M. Sinopse dos crustáceos decápodos brasileiros (Famílias Dorippidae e Leucosiidae). Cad. Ômega Univ. Fed. Rural PE., sér. Ciência. Aquát., Recife, n. 2, p.67-77, 1986.

MILNE EDWARDS, A. Reports on the results of dredging, under the supervison of Alexander Agassiz, in the Gulf of Mexico and in the Caribbean Sea, 1877, 78, 79. by the U. S. Coast Survey Steamer "Blake"... VIII. Études préliminaires sur les Crustacés. Bull. Mus. Comp. Zool., Harvard, v. 8, n. 1, p. $1-68,1880$.

MILNE EDWARDS, A.; BOUVIER, E. L. Reports of the results of dredging, under the supervision os Alexander Agassiz, in the Gulf of Mexico (1877-78), in the Caribbean Sea (1878-79), and along the Atlantic coast of the United States (1880), by the U. S. Coast Survey Steamer "Blake",... XXXIX. Les Dromiacés et Oxystomes. Mem. Mus. Comp. Zool., Harvard, v. 27, n. 1, p.1-127, 1902.

RATHBUn, M. J. The Oxystomatous and allied crabs of America. Bull. U. S. Natn. Mus., Paris, v. 166, p. 1-27, 1937.

SOUZA, J. A. J. Brachyura da plataforma meridional do Rio Grande do Sul, Brasil (Crustacea, Decapoda). Nauplius, Rio Grande, v. 5, n. 2, p.33-58, 1997 